\title{
The Fascinating Paradox of Osteoporosis in Axial Spondyloarthropathy
}

\author{
Gillian E. Fitzgerald and Finbar D. O'Shea
}

\begin{abstract}
Low bone mineral density (BMD) is a recognized feature of axial spondyloarthropathy (axSpA). However, the osteoproliferation inherent in axSpA can make traditional dual-energy x-ray absorptiometry assessment inaccurate, particularly in structurally advanced disease. As a result, much about osteoporosis in axSpA is unknown. There is a wide variation in prevalence figures for low BMD in the literature. There is also no consensus regarding risk factors for developing low BMD in axSpA. It is accepted that there is an excess of vertebral fractures in patients with axSpA, but the role of low BMD in contributing to this risk is virtually unknown. This article provides a comprehensive review of the current knowledge regarding low BMD in axSpA. It highlights our current BMD measurement techniques along with their potential pitfalls, and discusses the significance of BMD in vertebral fractures. It also identifies gaps in our knowledge and makes recommendations for future research. (First Release October 1 2017; J Rheumatol 2017;44:1767-76; doi:10.3899/jrheum.170051)
\end{abstract}

Key Indexing Terms:

AXIAL SPONDYLOARTHROPATHY BONE MINERAL DENSITY

Osteoporosis can be defined as "a systemic skeletal disease characterized by low bone mass and microarchitectural deterioration of bone tissue, with a consequent increase in bone fragility and susceptibility to fracture" 1 . It is a recognized entity in many inflammatory diseases. In rheumatoid arthritis, it is widely accepted that low bone mineral density (BMD) is an extraarticular feature of the disease ${ }^{2}$, with the prevalence of osteoporosis up to twice that of the general population and an increased risk of fractures. Similar data have been shown in juvenile idiopathic arthritis, where generalized loss of BMD and an excess of fractures, both vertebral and nonvertebral, are noted ${ }^{3}$. In psoriatic arthritis, the data are less robust, but point toward a high prevalence of low $\mathrm{BMD}^{4}$.

\section{BMD in Axial Spondyloarthropathy}

There is growing interest in BMD in axial spondyloarthropathy (axSpA). It is now accepted that patients with axSpA have a higher prevalence of both osteopenia and osteoporosis, when compared to age- and sex-matched controls. However, the reported prevalence of low BMD varies widely, ranging from $4 \%$ to $58 \%$ (Table 1$)^{5-30}$. There

From the Department of Rheumatology, St. James's Hospital, Dublin, Ireland.

G.E. Fitzgerald, MB, BCh, BAO, MRCPI, Rheumatology Specialist, Registrar, Department of Rheumatology, St. James's Hospital; F.D.

$O$ 'Shea, $M B, B C h, B A O$, MRCPI, Consultant Rheumatologist and General Physician, Department of Rheumatology, St. James's Hospital.

Address correspondence to G.E. Fitzgerald, Department of Rheumatology, St.James's Hospital, Dublin 8, Ireland.E-mail: GiFitzgerald@stjames.ie Accepted for publication July 11, 2017.

\section{OSTEOPOROSIS}

\section{DUAL-ENERGY X-RAY ABSORPTIOMETRY}

are many reasons underlying this discrepancy. First, there is a wide variation in the patient recruitment techniques used. Second, different techniques are used to evaluate BMD. A further confounder is the change in classification criteria published by the Assessment of Spondyloarthritis International Society in $2009^{31}$. Older studies exclusively used patients with ankylosing spondylitis (AS) as defined by the modified New York criteria, whereas newer ones use a combination of patients with axSpA and patients with AS. All these factors make it difficult to compare the existing literature accurately, thus limiting our understanding of the scale of the problem.

There are many undisputed facts. Almost all the literature agrees that patients with established axSpA have a higher prevalence of low BMD than controls (Table 1). However, this problem is not restricted to late disease. $\mathrm{BMD}$ begins to decline early in the disease process, with low BMD evident in $40-50 \%$ of axSpA patients with an average disease duration of only 6 years ${ }^{29}$. A diagnosis of axSpA is associated with low BMD, regardless of disease duration. In fact, the presence of low BMD, defined as a $\mathrm{T}$ score of $\leq-2 \mathrm{SD}$, has been shown to have good predictive value (positive likelihood ratio of 2.6-3.1) in diagnosing axSpA in patients with suggestive symptoms ${ }^{12}$. Another study also found that patients with nonradiographic (nr)-axSpA had significantly lower lumbar spine BMD than patients with mechanical lower back pain ${ }^{5}$.

\section{Measurement Techniques to Detect Low BMD}

Currently, the gold standard for assessing BMD is posteroan-

Personal non-commercial use only. The Journal of Rheumatology Copyright (c) 2017. All rights reserved. 


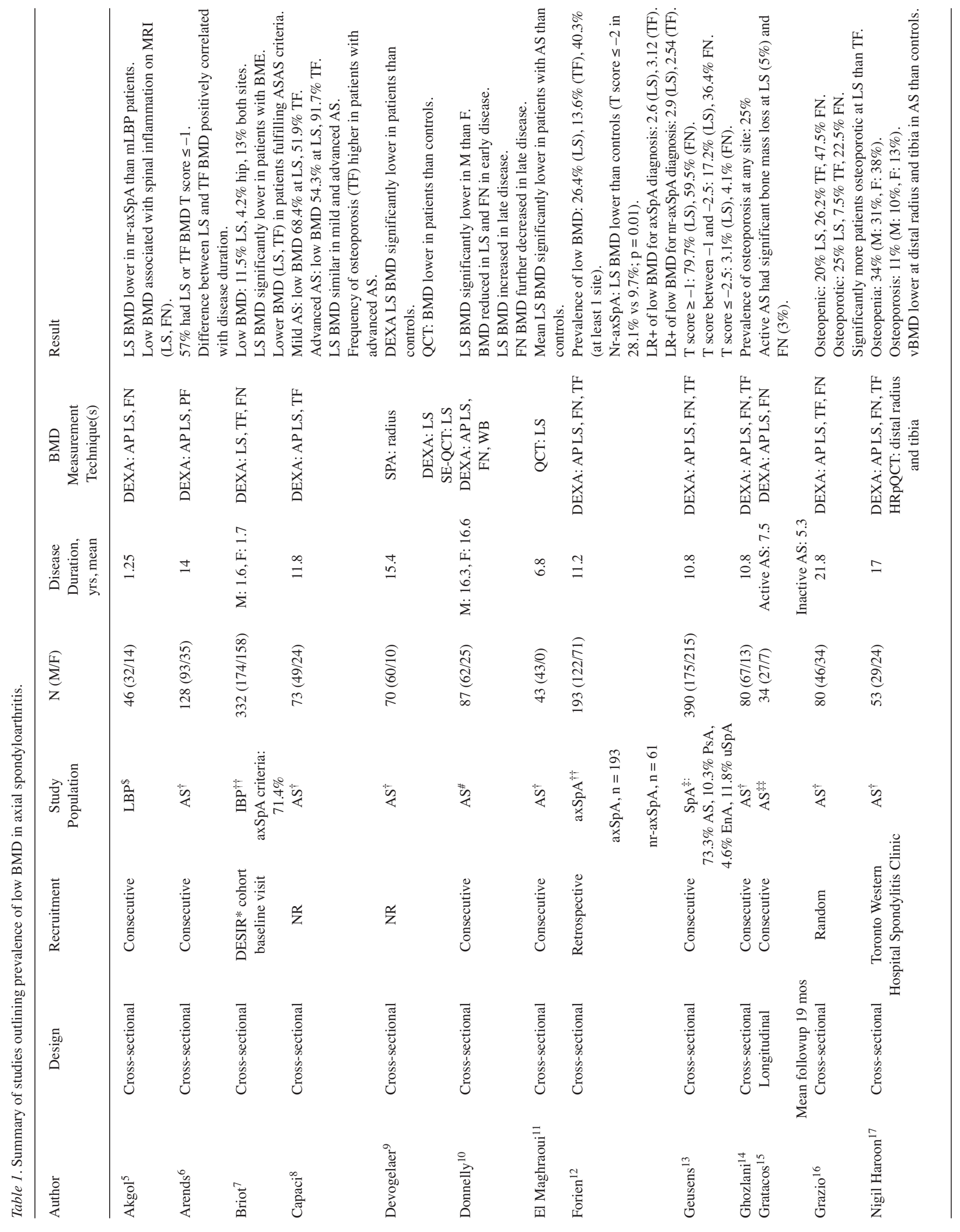




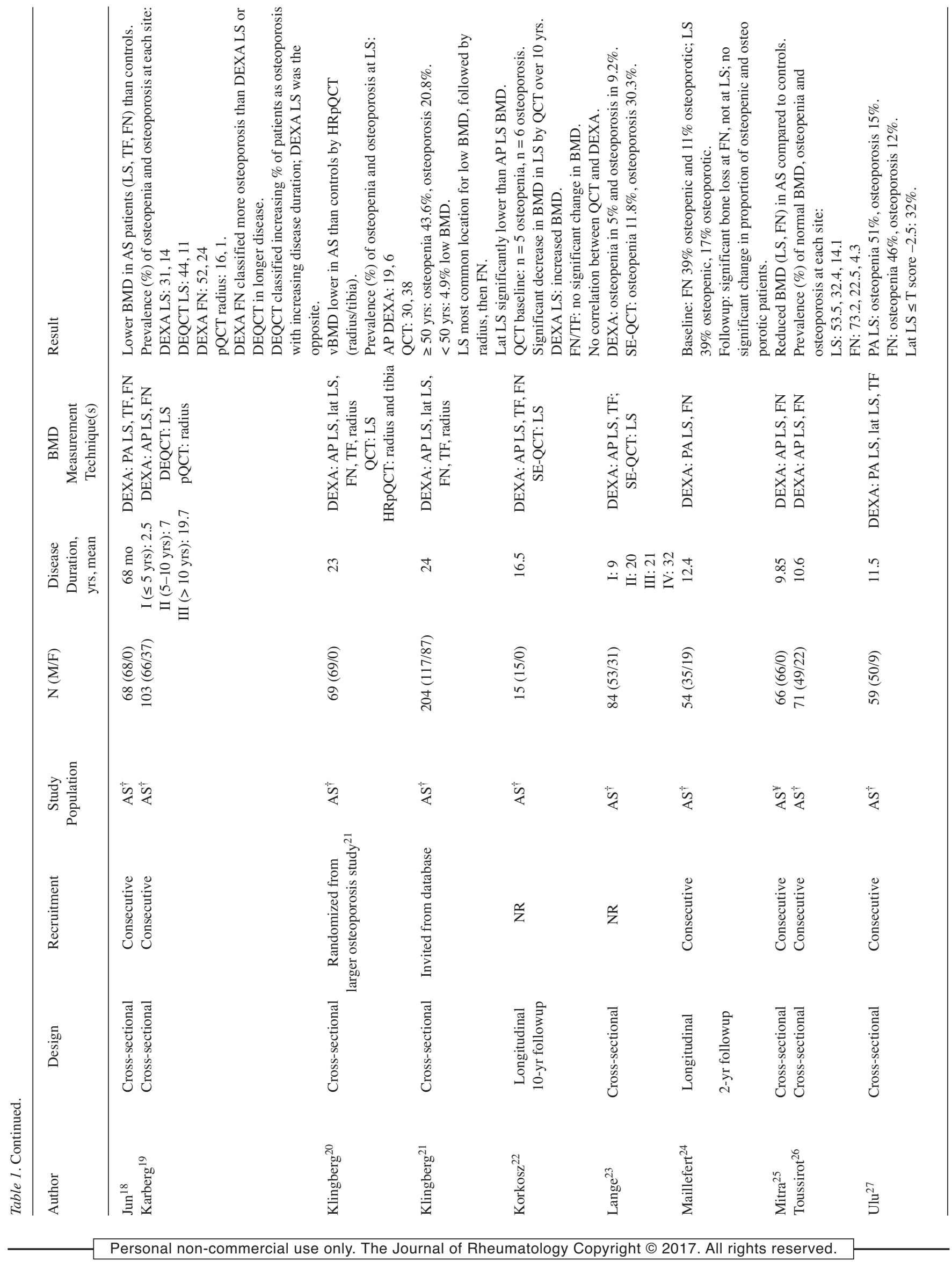

Fitzgerald and O'Shea: Osteoporosis in axSpA 


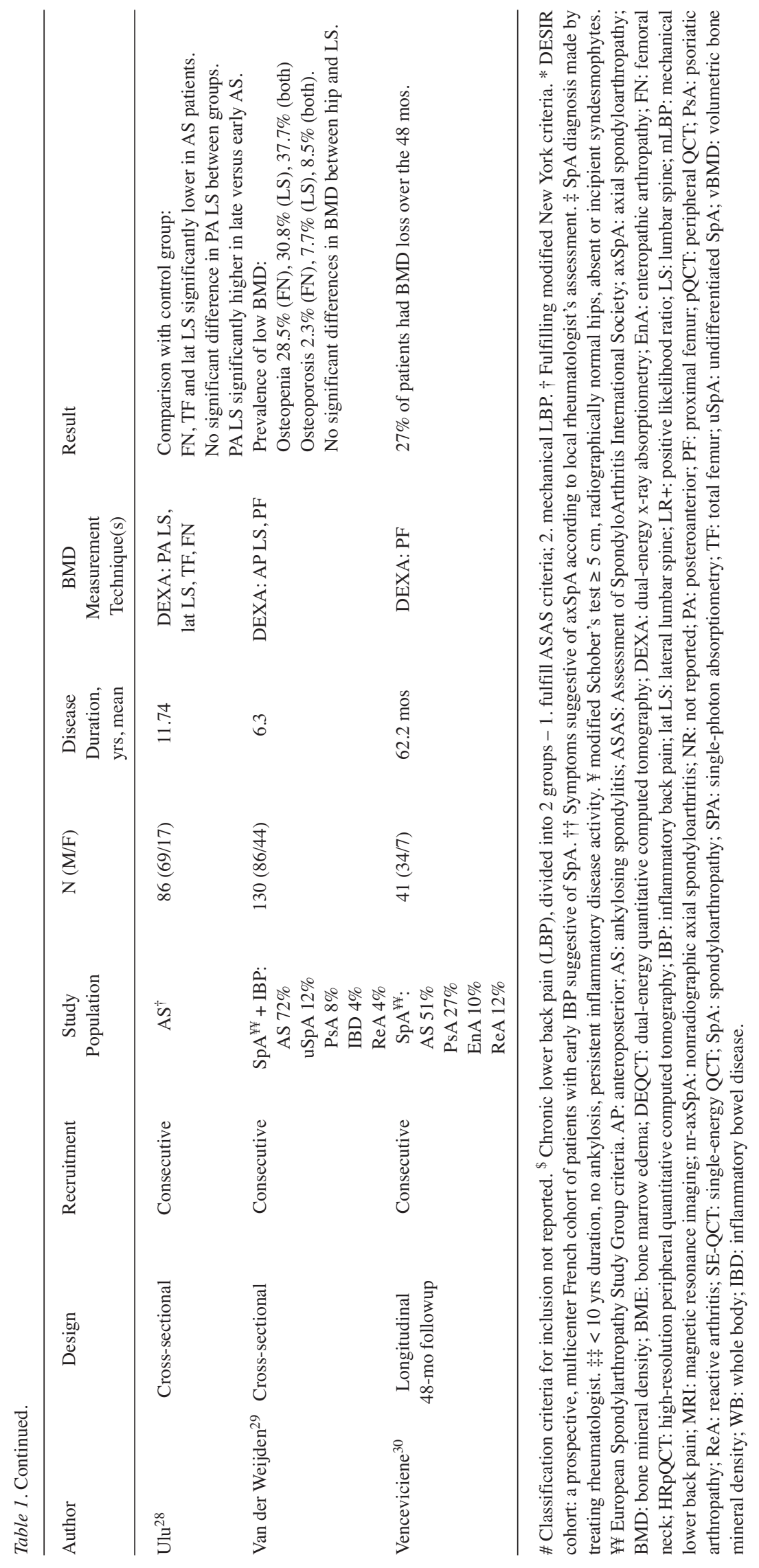

Personal non-commercial use only. The Journal of Rheumatology Copyright $\odot$ 2017. All rights reserved. 
terior (PA) dual-energy x-ray absorptiometry (DEXA) at the spine and hip, as recommended by the International Society of Clinical Densitometry (ISCD) ${ }^{32}$. However, the hallmark of axSpA is sacroiliitis and spinal damage due to both bony erosion and abnormal bone formation. This can lead to the development of syndesmophytes, perivertebral bone formation, ankylosis of the zygapophyseal joints, and pathologic new bone formation in the ligamentous apparatus. In severe cases, complete fusion of the spine can occur. This extensive osteoproliferation can falsely raise the BMD when PA (conventional) DEXA is used, giving an illusion of reassuringly normal BMD, even in cases where osteoporosis may be present. A study of 73 patients with AS using PA DEXA found that the frequency of low BMD in patients with mild disease was $68.4 \%$ in the lumbar spine, but the prevalence dropped to $54.3 \%$ in advanced cases ${ }^{8}$. This contrasted with the hip, where the prevalence increased from $51.9 \%$ in patients with mild disease to $91.7 \%$ in advanced cases. As the disease duration increased, there was a paradoxical rise in lumbar spine BMD, but decline of total hip BMD.

The optimal method to identify BMD loss is under dispute. The literature is conflicted as to whether BMD loss in axSpA is a local or systemic process. Low BMD was significantly more common in 103 patients with AS at femoral neck than at the lumbar spine, measured by DEXA or dual-energy quantitative computed tomography (DEQCT) ${ }^{19}$. However, another study of 71 AS patients with a mean disease duration of 10.6 years found that the prevalence of low BMD was higher than controls at the lumbar spine, but not at the femoral neck ${ }^{26}$. Yet other DEXA studies have shown the central and peripheral skeletons are equally affected by low $\mathrm{BMD}^{21}$.

In view of the limitations of traditional PA DEXA, alternative methods to assess BMD in patients with axSpA are clearly indicated. QCT has the advantage of measuring volumetric BMD (vBMD) without being affected by cortical artifacts, a technique that is highly attractive for patients with AS. In a study of 69 patients with AS, investigators found that QCT of the lumbar spine detected significantly more cases of osteoporosis and osteopenia than anteroposterior (AP) DEXA ${ }^{20}$. High-resolution peripheral QCT (HRpQCT), a newer technique that provides knowledge about bone microarchitecture, was also performed ${ }^{20}$. This demonstrated lower vBMD in the distal radius and tibia of patients with AS than in controls. It also demonstrated strong correlations between central and peripheral trabecular $\mathrm{vBMD}^{20}$, suggesting a systemic pattern of bone loss.

Although QCT of the lumbar spine has advantages over PA DEXA, the radiation dose associated with it makes safer methods desirable. Lateral DEXA scanning of the lumbar spine exclusively examines the BMD of the trabecular component of the bodies of the vertebrae, thus excluding the cortical-rich posterior components of the spine. Because osteoproliferation predominantly affects the cortical aspect of the spine, lateral DEXA should, in theory, be less affected by the changes that occur in the spine of patients with axSpA. Similar to axSpA, the degenerative changes that occur in the spine with age can also cause overestimation of BMD when using PA DEXA ${ }^{33}$. Lateral DEXA has been shown to identify more patients with age-related bone loss than AP conventional DEXA, in both men and women ${ }^{33}$. Previously, lateral DEXA was performed with the patient lying on their side. However, precision was very low and was deemed too insensitive to have any clinical use. The modern method to acquire lateral DEXA scans is that the arm of the DEXA scan is rotated $90^{\circ}$ and is obtained without the patient moving. Supine lateral measurements have been shown to offer similar precision to the standard AP DEXA scan ${ }^{34}$.

In AS, lumbar spine BMD was significantly lower with lateral DEXA measurement than with AP projection and significantly more cases of osteoporosis were detected $(26 \%$ vs $16 \%$; $p<0.001)^{21}$. Therefore, lateral DEXA is a promising tool to identify cases of osteoporosis without being affected by the osteoproliferation associated with axSpA.

Trabecular bone score (TBS) is a recently emerged tool obtained by reanalyzing AP lumbar spine DEXA images and evaluating variations in grey-level texture from pixel to pixel. It can distinguish between different microarchitectures that have the same bone density. The higher the TBS, the stronger the microarchitecture of the bone, which in turn is more resistant to fracture. In the general population, TBS is related to fracture risk ${ }^{35}$. There is a paucity of literature on axSpA, but 1 study showed that TBS was not influenced by syndesmophytes in contrast to AP DEXA measurement of the spine, although it did not identify prevalent fractures ${ }^{36}$. More research is needed to determine whether TBS would be a useful tool in patients with axSpA.

\section{Factors Associated with Low BMD}

The risk factors for reduced BMD are well outlined in the general population. Unfortunately, evidence supporting patient and disease characteristics associated with bone loss in axSpA is inconsistent (Supplementary Table 1, available from the authors on request) and largely based on crosssectional studies, where causal links are harder to establish.

Differences between the sexes. In the general population, women have a much higher risk of osteoporosis than men ${ }^{37}$. However, the current literature is conflicted regarding a male/female effect on BMD loss in patients with axSpA (Supplementary Table 1, available from the authors on request). Cross-sectional studies of AS patients with conventional DEXA measurements showed that male sex was associated with a lumbar or hip BMD T score of $\leq-1 \mathrm{SD}^{6}$ and the prevalence of low BMD in the spine was higher in $m^{27}$. However, a 4-year longitudinal study ${ }^{15}$ of patients with early AS demonstrated no sex effect on predicting bone loss, again as measured by conventional DEXA. A further longitudinal study of patients with axSpA, of whom $51 \%$ had

$$
\text { Personal non-commercial use only. The Journal of Rheumatology Copyright @ } 2017 \text {. All rights reserved. }
$$


AS, also found no sex effect on bone loss, although only BMD measurements of hips were performed ${ }^{30}$.

Perhaps this lack of effect is a bias owing to the historic underrecognition of axSpA in females and their subsequent underrepresentation in studies. As this disease is increasingly diagnosed in women, more robust studies with equal spread among men and women may answer this question more definitively. However, because the existing literature has an excess of men, it highlights that low BMD does indeed affect men with axSpA, a critically important point, because men and osteoporosis are not often thought of in the same sentence.

Disease duration. There is no consensus on the effect of disease duration on BMD, as illustrated in Supplementary Table 1 (available from the authors on request). As outlined earlier, BMD loss begins early in the disease course of both nr-axSpA and $\mathrm{AS}^{5,8,29}$. However, increasing disease duration is not consistently associated with worsening $\mathrm{BMD}^{26,27}$, but this likely reflects the difficulty in assessing BMD in late disease, owing to the higher prevalence of structural damage. The difference between PA lumbar spine and hip T scores measured by DEXA increases in tandem with disease duration ${ }^{6}$. However, lateral DEXA measurements appear to correlate better with disease duration ${ }^{28}$.

$B A S D A I$. One of the most frequently used tools to assess disease activity is the Bath Ankylosing Spondylitis Disease Activity Index (BASDAI), a patient-reported outcome $(\mathrm{PRO})^{38}$. Many DEXA studies, both cross-sectional ${ }^{21}$ and longitudinal ${ }^{15}$, have found no correlation between BMD and BASDAI. There are a few notable exceptions, however. One cross-sectional study measured BMD of the lumbar spine with $\mathrm{QCT}^{39}$ and found a higher mean BASDAI in patients with osteoporosis of the spine than without ( 8 vs 4 ; $p<0.05$ ). Conversely, Arends, et $a l^{6}$ found that when patients with AS were categorized as low BMD if the T score of the lumbar spine or hip was $\leq-1$ SD by DEXA, then a lower BASDAI was independently associated with low BMD (hip or spine).

A disadvantage of BASDAI is that it reflects the current disease activity and does not detect periods of potentially prolonged active disease in the past. Therefore, it is possible that a once-off calculation of BASDAI cannot predict BMD loss, but that the average score over time would be more useful. This hypothesis is supported by a 4-year longitudinal DEXA study of patients with $\mathrm{SpA}^{30}$, in which the patient group with more BMD loss had a higher average BASDAI score than those without BMD loss.

BASMI. The Bath Ankylosing Spondylitis Metrology Index (BASMI) is a validated tool to objectively assess spinal mobility ${ }^{40}$. Several cross-sectional studies have found an association between higher total BASMI and low BMD (Supplementary Table 1, available from the authors on request). A longitudinal study ${ }^{30}$ demonstrated that over 4 years, a deterioration in lateral flexion and intermalleolar distance readings of patients with $\mathrm{SpA}$ was associated with BMD loss at the hips (lumbar spine not assessed).

Inflammatory markers. Many studies (Supplementary Table 1), both longitudinal and cross-sectional, including DEXA and QCT, have found an association between higher C-reactive protein or erythrocyte sedimentation rate and lower BMD. However, to date, whether the addition of laboratory variables to PRO, in scores such as the Ankylosing Spondylitis Disease Activity Score, improves the predictive value of low BMD has not been investigated.

Radiological severity. From the Outcome Assessments in AS International Study cohort ${ }^{41}$, we know that more active disease is associated with progressive radiographic spinal change, as measured by the modified Stoke Ankylosing Spondylitis Spine Score (mSASSS) or the Bath AS Radiological Index (BASRI). The effect of radiographic damage on BMD is less clear (Supplementary Table 1, available from the authors on request). In the presence of syndesmophytes, more patients with AS had low BMD when measured by DEXA of femoral neck or DEQCT of lumbar spine than when AP DEXA of the spine was used ${ }^{19}$. After 10 years of disease duration, AP DEXA of the lumbar spine did not detect any cases of osteoporosis, and DEQCT at lumbar spine and DEXA of femoral neck were used instead. Another study using QCT to assess BMD of the lumbar spine showed that increasing mSASSS correlated significantly with a lower volumetric BMD in the lumbar spine ${ }^{20}$. In that study, peripheral bone microarchitecture, as measured by HRpQCT of the radius and tibia, was also worse in patients with more advanced structural damage, a finding supported by Nigil Haroon, et $a l^{17}$.

\section{Vertebral Fractures}

The clinical significance of osteoporosis is in the increased risk of fractures. In the general population, this risk is extremely well outlined ${ }^{37}$. It is less well defined in axSpA.

Multiple studies have shown that AS involves an increased risk of vertebral fractures (VF) compared to age- and sex-matched controls (Table $2^{42,43,44,45,46,47}$ ). It is also known that VF in patients with AS have a higher rate of complications, including devastating neurological outcomes ${ }^{48}$, than the general population. However, studies have demonstrated a wide variation in prevalence, anything up to $32 \%$ (Table 2). A large primary care-based case-control study in the United Kingdom ${ }^{47}$ selected 231,436 cases of fracture, vertebral and nonvertebral, recorded in the General Practice Research Database and matched with 231,362 controls. Patients with AS had an increased risk of clinical VF than controls, even when corrected for potential confounders (OR $3.26,95 \%$ CI 1.51-7.02). However, the risk of peripheral fractures in patients with AS was not increased, except in a subset that had a concomitant diagnosis of inflammatory bowel disease (OR 2.79, 95\% CI 1.10-7.08). A Swedish-based registry prospective study ${ }^{46}$ identified all patients with a primary

Personal non-commercial use only. The Journal of Rheumatology Copyright @ 2017 . All rights reserved. 


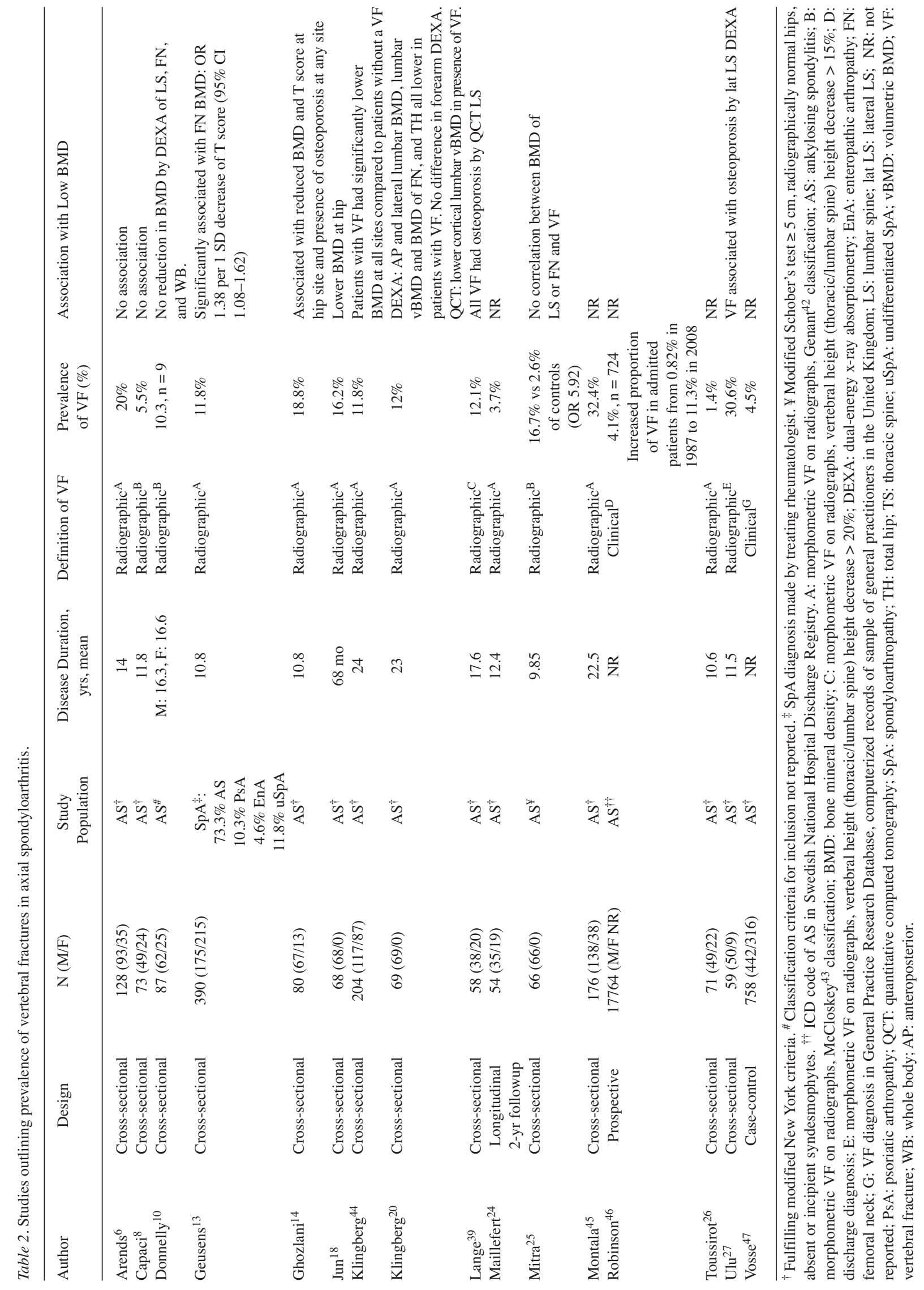

Personal non-commercial use only. The Journal of Rheumatology Copyright $\subset$ C 2017. All rights reserved. 
discharge diagnosis of VF and concomitant diagnosis of AS admitted between 1987 and 2008 and demonstrated a prevalence of $4.1 \%$ for clinical VF among patients with AS, with the proportion of fractures increasing throughout the 22 years of the study. However, registry-based data may underestimate the true prevalence of VF because VF do not always come to clinical attention, and prevalence on radiographic studies is much higher (Table 2).

The reason for the excess risk of VF in this population has not yet been fully elucidated (Supplementary Table 2, available from the authors on request). Cross-sectional studies demonstrated that radiographic detection of VF was correlated with radiological severity of AS, by mSASSS (OR $1.17,95 \%$ CI $1.05-1.3)^{14}$ and BASRI (OR $1.25,95 \%$ CI $1.12-1.39)^{45}$. BMD may also play a role in the excess risk of VF in patients with AS, as demonstrated by significant correlations between radiographic VF and BMD at all sites measured by DEXA (femoral neck, total hip, lateral lumbar $\mathrm{BMD}$, radius and AP lumbar BMD) ${ }^{44}$. However, in another study, only hip and lateral lumbar spine BMD were significantly lower in the radiographic VF group than in those without fractures ${ }^{28}$, with no correlation with AP lumbar spine BMD measurement. Yet other studies have shown no correlation between $\mathrm{VF}$ and $\mathrm{BMD}^{10}$. A study of 390 patients with axSpA found an increased risk of radiographic VF with lower femoral neck $\mathrm{T}$ scores ${ }^{13}$.

Low BMD is unlikely to fully explain the excess risk of VF, and decreased bone strength may play a role. HRpQCT of the distal radius and tibia demonstrated that patients with AS had worse microarchitecture (lower cortical and total vBMD, reduced cortical thickness, increased cortical porosity) than patients without AS, despite there being no difference in BMD by DEXA between groups at either the radius or lumbar spine ${ }^{17}$. In another study, male AS patients with VF demonstrated significantly worse peripheral bone microarchitecture (as measured by HRpQCT of the distal radius and ulna) than AS patients without a $\mathrm{VF}^{20}$.

Although the cause of VF is likely multifactorial, until our assessment techniques for detecting low BMD in AS are improved and standardized, it will be difficult to determine exactly what role BMD plays in the excess risk of VF that exists in this population.

\section{EULAR Guidelines}

In 2015, the European League Against Rheumatism (EULAR) published guidelines regarding imaging in $\operatorname{axSpA}^{49}$ that acknowledged the influence of radiographic change on evaluating BMD. This led to the recommendation that hip and AP DEXA be used in patients without syndesmophytes on conventional radiography. In patients with syndesmophytes, hip DEXA should be used, supplemented by either lateral DEXA or QCT. They also recommended further research to determine which form of imaging provides the best clinical usefulness for the diagnosis and monitoring of low BMD in patients with axSpA.

These guidelines highlight the issue of low BMD in patients with axSpA, a critically important step considering that only $31.6 \%$ of rheumatologists indicated that assessing for osteoporosis was part of their routine management of patients with $\mathrm{AS}^{50}$. However, the guidelines are limited by the lack of evidence available. BMD loss tends to be a progressive process, particularly if untreated, and thus requires serial monitoring. ISCD guidelines state that the same machine should be used to monitor patients for BMD loss to allow for accurate comparisons ${ }^{32}$. However, inherent to axSpA is the progression of structural damage ${ }^{41}$. Therefore, if EULAR guidelines are strictly followed, AP DEXA will be used in early disease, whereas lateral DEXA or QCT will be used in later disease, which will not allow accurate comparison of BMD. Clearly, having a guideline that recommends one method of BMD assessment in the early stages of the disease and a different one in the later, more structurally advanced stages is less than ideal.

The inherent paradox of osteoproliferation and osteoporosis in axSpA hinders clinicians in accurately managing the bone loss that occurs in this population. It is largely undisputed that low BMD occurs in axSpA, but much more work needs to be done. The most pressing problem is the lack of a standardized and accurate method to detect low BMD in this population. This needs to be clarified, then validated in axSpA, to prevent both under- and overdiagnosis of osteoporosis in axSpA. Without this method, it will remain difficult to accurately define the extent of the problem, as well as to determine predictive factors, consequences, and the effect of treatment on BMD in axSpA.

\section{REFERENCES}

1. NIH Consensus Development Panel on Osteoporosis Prevention, Diagnosis, and Therapy. Osteoporosis prevention, diagnosis, and therapy. JAMA 2001;285:785-95.

2. Hauser B, Riches PL, Wilson JF, Horne AE, Ralston SH. Prevalence and clinical prediction of osteoporosis in a contemporary cohort of patients with rheumatoid arthritis. Rheumatology 2014;53:1759-66.

3. Huber AM, Ward LM. The impact of underlying disease on fracture risk and bone mineral density in children with rheumatic disorders: A review of current literature. Semin Arthritis Rheum 2016; 46:49-63.

4. Chandran S, Aldei A, Johnson SR, Cheung AM, Salonen D, Gladman DD. Prevalence and risk factors of low bone mineral density in psoriatic arthritis: A systematic review. Semin Arthritis Rheum 2016;46:174-82.

5. Akgol G, Kamanli A, Ozgocmen S. Evidence for inflammation-induced bone loss in non-radiographic axial spondyloarthritis. Rheumatology 2014;53:497-501.

6. Arends S, Spoorenberg A, Bruyn GA, Houtman PM, Leijsma MK, Kallenberg CG, et al. The relation between bone mineral density, bone turnover markers, and vitamin D status in ankylosing spondylitis patients with active disease: a cross-sectional analysis. Osteoporos Int 2011;22:1431-9.

7. Briot K, Durnez A, Paternotte S, Miceli-Richard C, Dougados M, Roux C. Bone oedema on MRI is highly associated with low bone

Personal non-commercial use only. The Journal of Rheumatology Copyright (C) 2017. All rights reserved. 
mineral density in patients with early inflammatory back pain: results from the DESIR cohort. Ann Rheum Dis 2013;72:1914-9.

8. Capaci K, Hepguler S, Argin M, Tas I. Bone mineral density in mild and advanced ankylosing spondylitis. Yonsei Med J 2003; 44:379-84.

9. Devogelaer JP, Maldague B, Malghem J, Nagant de Deuxchaisnes C. Appendicular and vertebral bone mass in ankylosing spondylitis. A comparison of plain radiographs with single- and dual-photon absorptiometry and with quantitative computed tomography. Arthritis Rheum 1992;35:1062-7.

10. Donnelly S, Doyle DV, Denton A, Rolfe I, McCloskey EV, Spector TD. Bone mineral density and vertebral compression fracture rates in ankylosing spondylitis. Ann Rheum Dis 1994;53:117-21.

11. El Maghraoui A, Tellal S, Chaouir S, Lebbar K, Bezza A, Nouijai A, et al. Bone turnover markers, anterior pituitary and gonadal hormones, and bone mass evaluation using quantitative computed tomography in ankylosing spondylitis. Clin Rheumatol 2005;24:346-51.

12. Forien M, Molto A, Etcheto A, Dougados M, Roux C, Briot K. Bone mineral density in patients with symptoms suggestive of spondyloarthritis. Osteoporos Int 2015;26:1647-53.

13. Geusens P, De Winter L, Quaden D, Vanhoof J, Vosse D, van den Bergh J, et al. The prevalence of vertebral fractures in spondyloarthritis: relation to disease characteristics, bone mineral density, syndesmophytes and history of back pain and trauma. Arthritis Res Ther 2015;17:294

14. Ghozlani I, Ghazi M, Nouijai A, Mounach A, Rezqi A, Achemlal L, et al. Prevalence and risk factors of osteoporosis and vertebral fractures in patients with ankylosing spondylitis. Bone 2009; 44:772-6.

15. Gratacos J, Collado A, Pons F, Osaba M, Sanmarti R, Roque M, et al. Significant loss of bone mass in patients with early, active ankylosing spondylitis: a followup study. Arthritis Rheum 1999;42:2319-24.

16. Grazio S, Kusic Z, Cvijetic S, Grubisic F, Balenovic A, Nemcic T, et al. Relationship of bone mineral density with disease activity and functional ability in patients with ankylosing spondylitis: a cross-sectional study. Rheumatol Int 2012;32:2801-8.

17. Nigil Haroon N, Szabo E, Raboud JM, McDonald-Blumer H, Fung $\mathrm{L}$, Josse RG, et al. Alterations of bone mineral density, bone microarchitecture and strength in patients with ankylosing spondylitis: a cross-sectional study using high-resolution peripheral quantitative computerized tomography and finite element analysis. Arthritis Res Ther 2015;17:377.

18. Jun JB, Joo KB, Her MY, Kim TH, Bae SC, Yoo DH, et al. Femoral bone mineral density is associated with vertebral fractures in patients with ankylosing spondylitis: a cross-sectional study. J Rheumatol 2006;33:1637-41

19. Karberg K, Zochling J, Sieper J, Felsenberg D, Braun J. Bone loss is detected more frequently in patients with ankylosing spondylitis with syndesmophytes. J Rheumatol 2005;32:1290-8.

20. Klingberg E, Lorentzon M, Gothlin J, Mellstrom D, Geijer M, Ohlsson C, et al. Bone microarchitecture in ankylosing spondylitis and the association with bone mineral density, fractures, and syndesmophytes. Arthritis Res Ther 2013;15:R179.

21. Klingberg E, Lorentzon M, Mellstrom D, Geijer M, Gothlin J, Hilme E, et al. Osteoporosis in ankylosing spondylitis - prevalence, risk factors and methods of assessment. Arthritis Res Ther 2012;14:R108.

22. Korkosz M, Gasowski J, Grzanka P, Gorczowski J, Pluskiewicz W, Jeka $S$, et al. Baseline new bone formation does not predict bone loss in ankylosing spondylitis as assessed by quantitative computed tomography (QCT): 10-year follow-up. BMC Musculoskelet Disord 2011;12:121.

23. Lange U, Kluge A, Strunk J, Teichmann J, Bachmann G.
Ankylosing spondylitis and bone mineral density - what is the ideal tool for measurement? Rheumatol Int 2005;26:115-20.

24. Maillefert JF, Aho LS, El Maghraoui A, Dougados M, Roux C. Changes in bone density in patients with ankylosing spondylitis: a two-year follow-up study. Osteoporos Int 2001;12:605-9.

25. Mitra D, Elvins DM, Speden DJ, Collins AJ. The prevalence of vertebral fractures in mild ankylosing spondylitis and their relationship to bone mineral density. Rheumatology 2000;39:85-9.

26. Toussirot E, Michel F, Wendling D. Bone density, ultrasound measurements and body composition in early ankylosing spondylitis. Rheumatology 2001;40:882-8.

27. Ulu MA, Batmaz I, Dilek B, Cevik R. Prevalence of osteoporosis and vertebral fractures and related factors in patients with ankylosing spondylitis. Chin Med J 2014;127:2740-7.

28. Ulu MA, Cevik R, Dilek B. Comparison of PA spine, lateral spine, and femoral BMD measurements to determine bone loss in ankylosing spondylitis. Rheumatol Int 2013;33:1705-11.

29. van der Weijden MA, van Denderen JC, Lems WF, Heymans MW, Dijkmans BA, van der Horst-Bruinsma IE. Low bone mineral density is related to male gender and decreased functional capacity in early spondylarthropathies. Clin Rheumatol 2011;30:497-503.

30. Vencevičienė L, Butrimienė I, Vencevičius R, Sadauskienė E, Kasiulevičius V, Šapoka V. Factors associated with bone mineral density loss in patients with spondyloarthropathies: A 4-year follow-up study. Medicina 2015;51:272-9.

31. Rudwaleit M, van der Heijde D, Landewe R, Listing J, Akkoc N, Brandt $\mathrm{J}$, et al. The development of Assessment of SpondyloArthritis international Society classification criteria for axial spondyloarthritis (part II): validation and final selection. Ann Rheum Dis 2009;68:777-83.

32. Schousboe JT, Shepherd JA, Bilezikian JP, Baim S. Executive summary of the 2013 International Society for Clinical Densitometry Position Development Conference on bone densitometry. J Clin Densitom 2013;16:455-66.

33. Finkelstein JS, Cleary RL, Butler JP, Antonelli R, Mitlak BH, Deraska DJ, et al. A comparison of lateral versus anterior-posterior spine dual energy $\mathrm{x}$-ray absorptiometry for the diagnosis of osteopenia. J Clin Endocrinol Metab 1994;78:724-30.

34. Blake GM, Jagathesan T, Herd RJ, Fogelman I. Dual X-ray absorptiometry of the lumbar spine: the precision of paired anteroposterior/lateral studies. Br J Radiol 1994;67:624-30.

35. Harvey NC, Gluer CC, Binkley N, McCloskey EV, Brandi ML, Cooper C, et al. Trabecular bone score (TBS) as a new complementary approach for osteoporosis evaluation in clinical practice. Bone 2015;78:216-24

36. Wildberger L, Boyadzhieva V, Hans D, Stoilov N, Rashkov R, Aubry-Rozier B. Impact of lumbar syndesmophyte on bone health as assessed by bone density (BMD) and bone texture (TBS) in men with axial spondyloarthritis. Joint Bone Spine 2017;84:463-6.

37. Johnell O, Kanis JA. An estimate of the worldwide prevalence and disability associated with osteoporotic fractures. Osteoporos Int 2006; 17:1726-33

38. Garrett S, Jenkinson T, Kennedy LG, Whitelock H, Gaisford P, Calin A. A new approach to defining disease status in ankylosing spondylitis: the Bath Ankylosing Spondylitis Disease Activity Index. J Rheumatol 1994;21:2286-91.

39. Lange U, Teichmann J, Strunk J, Muller-Ladner U, Schmidt KL. Association of 1.25 vitamin D3 deficiency, disease activity and low bone mass in ankylosing spondylitis. Osteoporos Int 2005; 16:1999-2004.

40. Jenkinson TR, Mallorie PA, Whitelock HC, Kennedy LG, Garrett SL, Calin A. Defining spinal mobility in ankylosing spondylitis (AS). The Bath AS Metrology Index. J Rheumatol 1994;21:1694-8.

41. Ramiro S, van der Heijde D, van Tubergen A, Stolwijk C, Dougados M, van den Bosch F, et al. Higher disease activity leads to more

Personal non-commercial use only. The Journal of Rheumatology Copyright $@$ $~ 2017$. All rights reserved 
structural damage in the spine in ankylosing spondylitis: 12-year longitudinal data from the OASIS cohort. Ann Rheum Dis 2014;73:1455-61.

42. Genant HK, Wu CY, van Kuijk C, Nevitt MC. Vertebral fracture assessment using a semiquantitative technique. J Bone Miner Res 1993;8:1137-48.

43. McCloskey EV, Spector TD, Eyres KS, Fern ED, O'Rourke N, Vasikaran S, et al. The assessment of vertebral deformity: a method for use in population studies and clinical trials. Osteoporos Int 1993;3:138-47.

44. Klingberg E, Geijer M, Gothlin J, Mellstrom D, Lorentzon M, Hilme E, et al. Vertebral fractures in ankylosing spondylitis are associated with lower bone mineral density in both central and peripheral skeleton. J Rheumatol 2012;39:1987-95.

45. Montala N, Juanola X, Collantes E, Munoz-Gomariz E, Gonzalez C, Gratacos J, et al. Prevalence of vertebral fractures by semiautomated morphometry in patients with ankylosing spondylitis. J Rheumatol 2011;38:893-7.
46. Robinson Y, Sanden B, Olerud C. Increased occurrence of spinal fractures related to ankylosing spondylitis: a prospective 22-year cohort study in 17,764 patients from a national registry in Sweden. Patient Saf Surg 2013;7:2.

47. Vosse D, Landewé R, van der Heijde D, van der Linden S, van Staa TP, Geusens P. Ankylosing spondylitis and the risk of fracture: results from a large primary care-based nested case-control study. Ann Rheum Dis 2009;68:1839-42.

48. Westerveld LA, Verlaan JJ, Oner FC. Spinal fractures in patients with ankylosing spinal disorders: a systematic review of the literature on treatment, neurological status and complications. Eur Spine J 2009;18:145-56.

49. Mandl P, Navarro-Compan V, Terslev L, Aegerter P, van der Heijde D, D'Agostino MA, et al. EULAR recommendations for the use of imaging in the diagnosis and management of spondyloarthritis in clinical practice. Ann Rheum Dis 2015;74:1327-39.

50. Bessant R, Harris C, Keat A. Audit of the diagnosis, assessment, and treatment of osteoporosis in patients with ankylosing spondylitis. J Rheumatol 2003;30:779-82. 